\title{
Percepción, desecación y revitalización cultural ${ }^{*}$
}

\author{
María de los Angeles VillasecA**
}

\section{RESUMEN}

El fenómeno de la desertificación en el norte chileno se extiende cada día más y sus consecuencias no se reducen sólo a un problema medioambiental. Este fenómeno se ha constituido, desde el punto de vista antropológico, en el principal factor de impacto que han vivido las comunidades indígenas y mestizas de la precordillera y altiplano chileno, impacto que atenta contra su desarrollo y continuidad, tanto económico como cultural (Pourrut y Núñez 1995). Estudios realizados desde la década de los '60 señalan que el proceso de aculturación generado por la reducción de los recursos básicos de las comunidades andinas es sostenido y que la pérdida de identidad y de costumbres ancestrales es inevitable. Sin embargo, se ha detectado a nivel local la pervivencia de los sistemas de creencias y rituales que están en estrecha vinculación con la producción agropecuaria, en la que participan incluso los miembros de la comunidad que residen en los centros urbanos, poniendo en cuestión esas proyecciones y dando cuenta de un proceso de revitalización cultural gatillado, precisamente, por las presiones externas que constriñen el desarrollo tradicional de esas comunidades.

\section{ABSTRACT}

The phenomenon of turning land into a desert in Northern Chile grows each day and its

Este estudio se realizó dentro de los marcos del proyecto "Ciencia Indígena en los Andes de Sudamérica: etnobotánica de las Tierras Altas del Norte de Chile" (FONDECYT No 1970908).

Arqueóloga y licenciada en Antropología, Universidad de Chile. consequences are not reduced only to an environmental problem. This phenomenon became, from the anthropological point of view, the main impact factor that the native and halfcasted communities of premountain range and Chilean altiplano have borne; this impact attempts, economically and culturally, against their development and continuity (Pourrut y Núñez 1995).

The studies carried out since the 60's show that the acculturation process generated by the reduction of basic resources in the indian communities is continuous and the lost of identity and ancestral customs became inevitable. However, it has been detected at local level the survival beliefs and rituals that are tightly linked with agricultural productions, in which, even the members of the community who live in the urban centers take part. This casts doubts on those projections and tell us about a process of cultural revitalization caused, precisely, by the outside pressures that restrict the traditional development of those communities.

\section{Introducción}

En una de las regiones más áridas del planeta, las comunidades agropastoriles del área dependen en forma importante de las fuentes permanentes de agua -ríos, lagos, vegas y bofedales, entre otros-. Sin embargo, en las últimas décadas, las comunidades del Norte Grande han vivenciado la disminución de este recurso vital de subsistencia. A los cambios climáticos que van acentuando las condiciones de extrema aridez, se suman las extracciones de agua para proveer a los centros urbanos y los enclaves mineros, ya sea a través de usos no regulados o por concesiones de los respectivos derechos (Aldunate 1985; Castro, M. et al. 1991; 
Cavieres 1995; Gundermann y González 1995; Núñez 1995; van Kessel 1985). Muchas comunidades rurales de la I y la II región se ven afectadas por este problema, a tal punto, que se ha tratado de cautelar el acceso a las fuentes de agua por medio de la Ley de Pueblos Indígenas (Ley N ${ }^{\circ} 19.253$, arts. 63,64 y $3^{\circ}$ transitorio), aunque sus esfuerzos han sido infructuosos frente a las prerrogativas con que cuenta la actividad extractiva debido a los beneficios económicos que el sector minero genera al país (Pourrut 1995: 12).

Esta situación está produciendo fuertes trastornos medioambientales que no sólo han tocado el desarrollo económico y las formas de explotación tradicional del ambiente de desierto, sino que también ha afectado de manera importante la reproducción social y cultural de los poblados indígenas y mestizos de esta región. A la baja productividad que tienen los suelos y la actividad ganadera, se suma la migración, muchas veces sin retorno, de la población activa y de los niños, los que gradualmente van perdiendo su vinculación con la tierra de sus ancestros (cf. Hidalgo 1992; Misetic 1991, citado en U. de Chile 1997:109; Rivera 1995). Ante la evidente paradoja que se presenta al constatar un proceso de desestructuración económica y la recuperación de la actividad ritual tradicional -patente manifestación de continuidad cultural-, surge la necesidad de aclarar cómo las comunidades andinas perciben la transformación de su entorno, en qué grado y cómo se están viendo afectadas concretamente. Si bien es cierto que como tendencia general se prevé el paulatino desmembramiento y abandono de sus economías tradicionales, a nivel local se aprecia que otros órdenes de la cultura están presentando gran resistencia, relativizando esta tendencia general. Por consiguiente, se hace urgente volver a abordar el estudio de comunidades andinas desde sus múltiples perspectivas, complementando el análisis de sus sistemas productivos con los de sus sistemas simbólicos y sociales, órdenes en los que es posible entrever algunas vías de adecuación que limite el proceso de desestructuración y desaparición.

Gran parte de los estudios relacionados con el impacto y la relación que existe entre la población y el recurso agua en las comunidades atacameñas, se han realizado en centros de concentración demográfica rural, especialmente en los po- blados y ayllos del salar de Atacama. En esos estudios se ha verificado una importante diferenciación interna, la que se refiere tanto a aspectos relacionados con productividad agropecuaria y organización social como a la disponibilidad, calidad y control de los recursos básicos disponibles (agua y tierra). Frente a esta situación creemos que es oportuno abordar nuevas investigaciones desde la perspectiva del estudio de caso, analizando problemas puntuales en comunidades o unidades territoriales más pequeñas. Esto permitirá asegurar un grado relativamente mayor de homogeneidad intracomunitaria, lo que facilitará la aislación de variables relevantes y la distinción de algunos factores de cambio que inciden tanto en la percepción del medio ambiente como del impacto que producen sobre él las acciones que ejerce la sociedad nacional a través de los enclaves mineros y los centros urbanos regionales.

\section{Algunas consideraciones teóricas}

La evaluación del impacto social y cultural de una comunidad requiere, en primer término, de una definición de los parámetros que se consideran como elementos constitutivos de ella. Sólo esta distinción permite establecer el grado y el carácter de una transformación o de una desestructuración sociocultural. Asimismo, esta evaluación debe considerar la naturaleza y dinámica de los cambios que es posible percibir en una sociedad expuesta al contacto con otras, cuyas orientaciones económicas, sociales y de cosmovisión son diferentes a las locales, presionando, directa o indirectamente, para consolidar el proceso de integración a la sociedad mayor o nacional.

El aspecto fundamental de una comunidad es su conformación a base de una organización comunal y de unidades familiares que cuentan con un territorio colectivo (Plaza y Francke 1981: 57). En la actualidad, a este nudo central se le suma un nuevo nivel de articulación, que se refiere a las relaciones y la dinámica que se genera con la sociedad global, representada tanto en las instituciones estatales (en las que destaca el rol de las Fuerzas Armadas en las zonas de frontera), como en las entidades privadas que han establecido en sus inmediaciones enclaves de producción. Ambas lógicas se interdigitan en la orgánica de estas comu- 
nidades, pudiendo encontrar, en los niveles más complejos de organización interna, los nexos que estructuran las formas de interrelación o integración con la sociedad nacional.

Ante esta complejidad, creemos preciso distinguir, analíticamente, el nivel interno de una comunidad del externo. La organicidad intracomunitaria está definida por una relación necesaria entre lo comunal y lo familiar, que permite el desarrollo de cada unidad productiva en coexistencia, equilibrio y cooperación con otras unidades. Lo familiar se orienta a la subsistencia económica de la unidad campesina, ya que la producción familiar se logra por medio del trabajo conjunto de todos sus miembros -mano de obra congregada por parentescoy labores en las que participan según los grados de cooperación y reciprocidad que este sistema señala; en tanto que lo comunal se encarga de regular las relaciones que pueden darse entre las distintas unidades familiares que comparten el territorio, ejerciendo, así, funciones de control, organización, representación y defensa de las unidades familiares y de su conjunto.

Por otra parte, es preciso recordar que el proceso de aculturación no implica un cambio progresivo y lineal que termina, necesariamente, por destruir y borrar a la cultura o sociedad que se encuentra bajo su impacto. La aculturación es, por definición, un fenómeno dinámico en el que los procesos de integración, resemantización y reinterpretación cultural van a la par con el abandono de determinadas costumbres y las transformaciones de algunas percepciones (Aguirre Beltrán 1957; Bonfil 1991). Este es el punto teórico más relevante que se debe considerar en un estudio sobre las percepciones de los cambios que experimenta un grupo humano determinado, ya que en ellas se deben manifestar tanto los nuevos elementos culturales, adquiridos de la sociedad mayor que los presiona, y las cosmovisiones tradicionales, en grados distintos, los que deben ser evaluados caso a caso.

\section{Percepción cultural y recursos}

La apropiación cultural del entorno ha permitido, por siglos, el desarrollo de las comunidades andinas, superando las adversas condiciones medioambientales, adaptándolo a sus estrategias de explotación y adaptándose a sus ciclos y a los recursos que ofrece. De esta manera, estas comunidades han generado un profundo conocimiento del medio físico en que se desenvuelven, dominando -al menos conceptualmente- sus condiciones "objetivas" y resemantizándola subjetivamente.

A nivel de ecología objetiva (sensu Watanabe 1964) se puede observar una composición vegetacional que se corresponde con una división por pisos o gradiente altitudinal -pisos preandino, puneño, altoandino y subnival-, la que se ve complementada por una percepción ecológica subjetiva de tipo vertical (Vallée 1970). Este sistema de etnoclasificación suma características de conformación geográfica y botánica, que en la región de El Loa Superior se manifiesta en la distinción de una serie de unidades ecológicas (Aldunate $e t$ al. 1981: 191-194). Esas categorías estructuran su percepción del entorno entrelazando perfecta y armoniosamente lo funcional-económico con lo sacro y propiamente simbólico. Esta complejidad es de carácter tal que algunos investigadores han preferido trabajarlas como una sola gran unidad de análisis, denominándolas "tecnologías simbólicas" (van Kessel 1992). Nuestra experiencia de campo confirma la existencia de esta interdigitación; sin embargo para poder resolver las cuestiones que nos convocan, hemos tenido que disectar analíticamente las etnoclasificaciones de las ritualizaciones que llevan aparejadas, a la vez que hemos tenido que omitir muchos de los aspectos propios de una cosmovisión como la andina, al registrar cada categoría de percepción espacial, para centrar el estudio sólo en lo que dice relación al medio ambiente y sus recursos.

La dimensión simbólica no es entendible desde los criterios de productividad occidental, pero para las comunidades andinas son parte misma del sistema económico, de reproducción social y cultural. De esta manera, perciben que su prosperidad depende de la relación que establezcan con la Tierra, el Agua y los Cerros, no como unidades físicas, sino como seres protectores, pero siempre duales, con los que debe convivir día a día. Esta relación se evidencia en los pagos rituales que se les hacen a estos seres tutelares y en las restricciones conductuales que se tienen con respecto al tránsito, uso y trato con ellos (cf. Castro y Martínez 
1996; Castro, V. y Varela 1995; Flores Ochoa 1968; Mariscotti 1978; Martínez, G. 1976; 1983; Tomoeda 1988; Reinhard 1983; van Kessel 1990; 1992; 1996a; van Kessel y Condori 1992). A esto debemos agregar la vinculación con los antepasados mediatos y remotos de la comunidad, como proveedores y mantenedores de los recursos con que se cuentan (Martínez, G. 1976).

\section{Marco de realización de la investigación}

La investigación tuvo lugar en los sectores de Pastos Grandes y Santa Bárbara (comuna de Calama, Prov. de El Loa, II Región), que en términos geográficos están comprendidos entre la quebrada Salvero ( $\left.21^{\circ} 43^{\prime} ; 68^{\circ} 39^{\prime}\right)$ y el cruce del ferrocarril internacional Antofagasta-Bolivia (21 ${ }^{\circ} 59^{\prime}$; $68^{\circ} 36^{\prime}$ ), distante unos $68 \mathrm{~km}$ al NE de la ciudad de Calama, $13 \mathrm{~km}$ al E del pueblo de Conchi Viejo y $8 \mathrm{~km}$ al SO de la estación ferroviaria San Pedro. El territorio así definido corresponde a unos $30 \mathrm{~km}$ lineales, cuya altitud promedio oscila entre los 3.000 y $3.350 \mathrm{~m}$. snm (ver mapa 1). La población de estos sectores forma parte de los comuneros de Conchi Viejo, los que aún mantienen sus actividades tradicionales y su condición de campesinos. La elección de esta comunidad como centro para este estudio estuvo guiada por su homogeneidad interna, dado que todas las unidades productivas domésticas (UPD) se desenvuelven bajo una orientación predominantemente pastoril y por su emplazamiento en una zona de reactivación minera y de captación de agua, para uso industrial y urbano.

\subsection{Medio ambiente y desertificación local}

Este tramo de valle del río Loa se caracteriza por tener una clara orientación N-S, por lo que no se registran grandes diferencias altitudinales en su interior, aun cuando la pampa se ve delimitada por desarrollos precordilleranos tanto hacia el E como el $\mathrm{O}$, los cuales determinan la presencia de una gradiente altitudinal bastante marcada si consideramos un espacio mayor y no sólo el tramo de valle aludido.

La situación climática de estos sectores destaca por su carácter ecotonal, ya que se localizan en una zona limítrofe entre el desierto absoluto y el desierto marginal de altura. El régimen de lluvias es estival y de volumen muy reducido, agravado por los extensos períodos de sequía que se registran en la región. Este hecho aumenta la importancia del río Loa como recurso hídrico permanente, más aún debido a que en este tramo sus aguas presentan una mejor calidad -en cuanto a nivel de sales y arsénico- para el consumo humano y animal. Estos factores se conjugan para producir una vegetación zonal arbustiva rala en que predomina la rica-rica (Acantholippia deserticola); mientras que en el interior del valle, tienen especial relevancia las formaciones vegetacionales de tipo azonal, presentándose en forma de vega de caja de río, la que se compone de diversas gramíneas: cortadera (Cortaderia atacamensis), unquillo (Juncus balticus Willd) y grama (Distichlis humilis y spp.) entre otras. La fauna presente consiste en algunas ánades migratorias, pequeños roedores, chinchillas (Abrocoma) y vizcachas (Lagidium viscacia), en lo que podríamos llamar "fauna menor"; con algunas aves de mayor tamaño, como el suri, y algunas tropillas de camélidos no-domésticos, como el guanaco (Lama guanicoe). Existen en el sector otros animales de importancia, como son los dos mayores depredadores locales: el zorro (Dusicyon sp.) y el cóndor (Vultor gryphus) (Ciren-Corfo 1976; Consecol 1988; Essan 1992).

La presencia humana, que se remonta al menos al período Arcaico (cf. Aldunate et al. 1986; Castro et al. 1994; L. Núñez 1965; Mostny y Kunsemuller 1960; Rydén 1944), ha ido alterando la distribución y composición de los recursos fáunicos y vegetacionales. Sin embargo, es en este último siglo cuando más se ha afectado el paisaje local, teniendo entre uno de los factores más relevantes a considerar las extracciones de agua del río Loa y de sus afluentes.

Según se registra en la División General de Aguas, las concesiones de este recurso alcanzan los $4.518,5$ 1/seg. considerando sólo las captaciones que afectan directamente a nuestra área de estudio, valor que puede elevarse a más de 13.000 $1 /$ seg. si consideramos las extracciones que indirectamente disminuyen el volumen de agua o de pasturas a los que recurren los estancieros altoloínos en cuestión, tanto por extracciones en napas subterráneas y de humedales. Estos valores son muy altos si se considera que el caudal medio del río Loa es de 200 1/seg. en sus nacientes, valor 
que aumenta a unos $510 \mathrm{l} / \mathrm{seg}$. en Lequena y a 1.800 1/seg. en Conchi. Tanto es así, que si se realiza un estudio histórico sobre los caudales del río Loa, previo a las captaciones y en su estado actual, podemos observar que éste ha disminuido en un 45,9\% entre los años 1985 y 1996, según las mediciones efectuadas en la salida del embalse Conchi, disminución que no se relaciona con disminuciones naturales del caudal, ya que en el tramo anterior a la represa de Lequena la variación producida fue de sólo un 9,9\% en igual período.

Las grandes excepciones anuales provienen de los eventos de crecida que registra el río Loa debido a los deshielos cordilleranos, siendo la de la década del '20 y la del año 1961 las más relevantes, aun cuando se han registrado episodios menores en 1974. Estos fenómenos fluviométricos han permitido que el Loa renueve su caudal de manera importante, alimentando las napas subterráneas. Pese a su carácter fortuito, su ocurrencia no deja de tener consecuencias -favorables y desfavorablespara la población local. Por un lado, las grandes crecidas del río han inundado todo el piso del valle en sólo unas pocas horas, lo que trae consigo aislamiento y pérdida de ganados e infraestructura a los estancieros; aunque, simultáneamente, permite que, una vez retiradas las aguas, el área de crecimiento vegetacional se extienda más allá de la orilla inmediata del curso de agua, lo que redunda en unos años con mejores forrajes en el valle.

Desde mediados de la década del '80 hasta 1996 se produjo una sequía que fue mermando las cubiertas vegetacionales del valle y de la pampa circundante e incluso desecó algunas aguadas (cf. Banco Nacional de Aguas, D.G.A., que cerró estaciones de medición en la subcuenca del Alto Loa).

La conjunción de estos factores geográficos (pluviosidad y características hidrológicas) con los de acción antrópica, como la tala de matorrales, el pastoreo y las extracciones de agua, han determinado que la región bajo estudio esté experimentando una desertificación acelerada, tal como se registra en el Diagnóstico de la desertificación en Chile (U. de Chile 1997).

\subsection{La comunidad de Conchi Viejo: Características generales}

La comunidad de Conchi Viejo, como parte del mundo andino -y de las demás comunidades tradicionales- es un todo complejo e integrado que involucra una serie de niveles que nuestra cultura occidental tiende a segregar analíticamente. Es precisamente esta integración la que nos ha motivado a volver a estudiar el fenómeno del impacto cultural y los procesos de desestructuración, que han sido abordados parceladamente en estudios anteriores. Sin embargo, el fenómeno de aculturación que se manifiesta en las culturas indomestizas nos lleva a conservar las distinciones analíticas de los niveles ecológicos, económicos, sociales e ideológicos, para analizar la interdigitación de las tendencias de adopción, rechazo y contraaculturación que se producen en la comunidad bajo estudio, abriendo así las posibilidades de integrar el análisis en una visión holística en el último acápite de este escrito.

La comunidad local está conformada por un grupo de estancieros con orientación predominantemente ganadera y cuyos asentamientos conforman una serie de caseríos dispersos relativamente autárquicos. Su organización social preponderante se estructura en torno a lazos de parentesco basados en núcleos familiares cada vez más pequeños, cuya tendencia es la reducción de los caseríos a familias nucleares.

Así, a mediados de la década de los ' 90 en el sector bajo estudio encontrábamos una población permanente que no supera la decena de personas, en la cual predominan las mujeres adultas mayores de 45 años. La población infanto-juvenil es prácticamente nula, debido a la migración forzada para dar cumplimiento a las leyes del EstadoNación, que impone la educación formal obligatoria a partir de los 6 años (primero básico) y que debiera extenderse hasta que el niño culmine el segundo ciclo de educación básica. La inexistencia de centros educativos en el sector y la percepción de que la educación les dará mayores posibilidades explica que, habiendo escuelas en los poblados de Lasana y Chiu Chiu, los niños sean enviados a la ciudad de Calama, lugar en donde son cuidados por parientes. Allí son educados en " $\mathrm{co}$ sas de pueblo", regresando en las vacaciones de 
verano a las estancias. Sin embargo, con el correr de los años, los niños se han habituado a vivir en la ciudad y van distanciando las visitas a sus padres. Si bien las escuelas fiscales y, posteriormente municipales, de Calama no corresponden in estrictu sensu a escuelas de frontera, la formación que reciben en ella se enmarca en los parámetros valóricos de la sociedad nacional, y no se le da espacio ni expresión a las raíces indígenas que forman parte importante de su realidad de origen. El resultado es un progresivo proceso de asimilación cultural y desarraigo, que ya no sólo viene por el desapego a la tierra y a las labores económicas tradicionales -socialización que no se realiza por la distancia y el poco tiempo que permanecen con sus padres en las estancias-, sino también por el desconocimiento de la matriz simbólica que sustenta todas las relaciones que se producen al interior de las comunidades andinas o mestizas rurales.

Una vez que terminan sus estudios obligatorios -O desertan del sistema educacional-, los jóvenes no suelen retornar a las UPD (Unidades Productivas Domésticas, sensu Yacobaccio et al. 1994) enclavadas en el valle del río Loa, sino que se integran a la población económicamente activa de las mineras o en el área servicios, en la misma ciudad de Calama, en Chuquicamata o en Antofagasta. Sus trabajos no son bien remunerados, ya que pocos tienen la preparación que les permite integrarse al sistema productivo como obreros calificados; sin embargo, sus posibilidades de desarrollo económico son percibidas como mejores que reintegrándose a la comunidad rural de la que alguna vez formaron parte. Esta tendencia general se ve contradicha en un aspecto de importancia: muchas de las familias han logrado mantener lazos de dependencia económica mutua, por lo que en tiempos de baja de oferta laboral en la ciudad, conflictos de diversa índole o llegada la edad en que pasan a engrosar la población pasiva, retornan a las estancias de sus padres o reactivan antiguos asentamientos pastoriles en las cercanías a los de sus padres.

Aun cuando los lazos parentales estructuran a la población del sector y permiten el desarrollo económico de las UPD, la comunidad de Conchi Viejo mantiene un patrón de asentamiento disperso. Este se asemeja, en gran medida, a la situación descrita para la puna peruana y otras regiones de los Andes (Flannery et al. 1989; Flores Ochoa 1964, 1968, 1983; Martínez 1976; Merlino 1979; Merlino y Rabey 1983; Palacios 1981, 1988; van Kessel 1996), en la que es posible distinguir unidades habitacionales y sus áreas de explotación, un pueblo al que se sienten vinculados y asentamientos secundarios de uso temporal.

Las estancias de los sectores que describimos corresponden a asentamientos permanentes ligados a la explotación ganadera, que, como señalábamos anteriormente, corresponden a unidades familiares. Estas estancias tienen bajo su control un radio cotidiano (play radius, sensu Binford 1982) que está representado por las estructuras de la vivienda, los corrales y las vías de circulación que unen todas estas áreas. Además es posible distinguir un radio de forrajeo natural y potreros (áreas de cultivo de forraje) a los que se recurre diariamente. Cada unidad familiar ha delimitado derechos de uso sobre las pasturas naturales que ofrece la vega de caja de río. Estos límites están marcados por cierres (pircas que cruzan transversalmente el valle), y que demarcan territorios de una extensión superior a los dos km lineales. El paulatino despoblamiento de estos sectores ha dejado obsoletos estos sistemas, ya que la presión por las pasturas y los requerimientos de normar su uso han disminuido, por lo que es común que las áreas de forrajeo se extiendan más allá de las marcas de los antiguos cierres.

Estos asentamientos pastoriles son utilizados durante todo el año, constituyéndose, en el lugar fijo de residencia de estos estancieros, un modelo característico de las tierras altas de Iquique, I Región (cf. Martínez 1976; Provoste 1976; 1979). Esta ocupación de carácter permanente se contrapone con el carácter regional atribuido a las estancias en otros lugares de la II Región (Aldunate y Castro 1981; Castro y Martínez 1996; Délano 1982; Gómez, C. 1980; Gundermann 1984; Uribe 1994), definiéndolas como lugares de explotación ganadera de uso temporal o estacional y que se registra en las comunidades de la cuenca del río Salado, las cuales desarrollan una actividad agrícola de mayor importancia que la que se registra en la comunidad de Conchi Viejo y que las ha configurado un sistema de asentamiento centrado en 
el poblado, con movilidad estacional a los puntos de forraje en la estación húmeda.

Los habitantes de Santa Bárbara y Pastos Grandes cuentan con un poblado, Conchi Viejo, en el cual adscriben sus orígenes y, por tanto, se ha convertido en un lugar que los une e identifica, dando nombre a la comunidad. Este pueblo surgió como un caserío minero, posiblemente a mediados o fines del siglo XVII, aunque los registros etnohistóricos sólo le dan relevancia como centro de explotación del cobre y otros minerales en el siglo XVIII (Casassas 1974:57).

Casi todos los habitantes del sector tienen allí una residencia, ya sea propia o de algún pariente cercano, en la que alojan cuando asisten a alguna celebración religiosa, como las fiestas de los Santos Patronos (p. e., San Juan Bautista), La Tirana Chica -de menor envergadura que la realizada en la I región de Chile y que corresponde a la fiesta de la Virgen del Carmen- y carnavales.

Finalmente, en cuanto a los asentamientos secundarios sólo podemos decir que están en franco retroceso, al menos en el uso de estos pastores, los que han concentrado sus actividades en el área de forrajeo que circunda su estancia, no habiendo necesidad de trasladarse a otro sector. La única excepción la encontramos en los pastores de Pastos Grandes, ya que la estrechez del valle no permite el desarrollo de una cubierta vegetacional extensiva que les permita mantener allí el ganado de manera constante, viéndose en la necesidad de trasladarse a otros sectores, ubicados al norte de nuestra área de estudio.

\subsubsection{Su organización productiva}

Como se ha podido apreciar, los estancieros de Pastos Grandes y Santa Bárbara tienen una economía basada principalmente en el pastoreo de ganados mixtos (llamas, ovejas y cabras) que se desarrolla bajo un sistema que puede definirse como uso intensivo del espacio. Esta estrategia de manejo del espacio físico y sus recursos corresponde a un sistema de pastoreo en el que el radio de forrajeo (sensu Binford 1982) se limita al valle la mayor parte del año y se extiende hacia el campo y cerro en la estación de lluvias. De esta forma, no se hace necesario generar de asentamientos secundarios para pastear a los animales, por lo que el patrón se ve reducido a un único asentamiento multifuncional, que incluye un área habitación, zonas de corrales y campos de cultivo.

Los niveles de productividades de las UPD son bajos y están destinados al autoconsumo. Sus masas ganaderas fluctúan entre 20 y 40 animales medianos (principalmente ovinos) y una a dos decenas de camélidos. De los subproductos que obtienen, la artesanía en lana registra una salida al mercado informal, ya sea por venta directa o por encargo que hacen los mineros o los parientes que han migrado a las urbes. Sólo en ocasiones excepcionales venden carne, la más de las veces "en pie", a los pescadores o a otras personas que llegan al sector con ese único fin.

Los niveles de autosustentación de los estancieros de Santa Bárbara y Pastos Grandes es bastante generalizado, complementando la actividad ganadera con una horticultura de subsistencia, la pesca y la caza fortuita. Es por esta razón que sólo van a la ciudad un par de veces al año a entregar los encargos que se les han solicitado en mantas y calcetines, dinero con el cual compran la mercadería que ellos no pueden preparar (azúcar, algunos farináceos, verduras y huevos).

Por otra parte, hemos constatado que la región en estudio -principalmente las localidades de Taira y La Isla-, es receptora de masas ganaderas que funcionan bajo una lógica de uso extensivo del espacio. Esto da origen a varias unidades de asentamiento de ocupación temporal, que dependen de una estancia o UPD ubicadas fuera de los sectores referidos e incluso de otras cuencas. Estas cabañas están conformadas por uno o dos cuartos y un corral de gran tamaño. Su finalidad es el aprovechamiento de zonas de pasturas a más de un día de distancia de la estancia o pueblo de origen, por lo tanto, este sistema de pastoreo incluye radios logísticos (sensu Binford 1982).

En términos generales, podríamos decir que la comunidad de Conchi Viejo mantiene ciertos niveles de autosuficiencia y aislamiento, lo que le permite desarrollar sus actividades tradicionales y su modo de vida. Sin embargo, también han creado lazos de dependencia con el mundo de la ciudad, tanto por la migración de la población infantil y productiva, como por la obtención de algu- 
nos productos básicos que no están en condiciones de producir o de conseguir, bajo los patrones tradicionales de colaboración, intercambio o reciprocidad, teniendo que participar, de algún modo, en el mercado. Estas necesidades se ven aumentadas cada día más por los requerimientos monetarios que surgen de tener a sus hijos en las ciudades e incorporados a establecimientos educacionales, viéndose impelidos a buscar una mayor participación en sistemas de intercambio monetario.

\subsection{Percepción de los cambios medioambientales}

Las condiciones medioambientales locales son medidas y cuantificadas por los estancieros altoloínos en función de dos de sus recursos básicos, los que a su vez son interdependientes: el agua y las pasturas. En las últimas décadas, los pastores han visto cómo los cursos estacionales de agua y algunas fuentes subterráneas han ido disminuyendo sus caudales o se han desecado. Esta situación afecta principalmente las aguadas u ojos de agua que se distribuían en la pampa y que les permitía desplazarse con tranquilidad a las pasturas estacionales, atravesando el páramo desértico que media entre el valle y los cerros, o que les permitía desarrollar actividades anexas al pastoreo, como el arrieraje y el caravaneo.

Este proceso de desecación se explica por las sequías que, según cuentan los propios estancieros, se ha llegado a prolongar por más de una década, lo que no sólo implica la no renovación de carga de los acuíferos regionales, sino que también una situación de estrés ambiental en el que las áreas de forraje natural se ven fuertemente afectadas. En primer término, la escasez absoluta de precipitaciones elimina la posibilidad de escurrimiento en las quebradas de flujo estacional, lo que significa una disminución del agua superficial y de la cubierta vegetacional que se desarrolla en estas quebradas intermedias. En segundo lugar, en las laderas de los cerros y la pampa no pueden brotar las gramíneas estacionales ni florecer las tolas que constituían un recurso forrajero de calidad altamente apreciado por los pastores, especialmente para el ganado camélido. En tercer lugar, a principios de la década de los '90, conjuntamente con la sequía, se registraron otros fenómenos climáticos que alteraron el normal desarrollo de la actividad pecuaria: al culminar el invierno, hubo nevazones de consideración, lo que, si bien representó un aporte de reservas de agua, afectó directamente el valle de El Loa, cuya vega, quemada al quedar cubierta por la nieve, se vio seriamente deteriorada tanto en términos de extensión como en calidad de los pastos que la conforman. Estas nevazones, ocurridas en septiembre de 1995, persisten como un referente de la inclemencia local del medio ambiente y de las dificultades con que se ven enfrentados cotidianamente los pastores altoloínos.

La falta de agua y de pasturas de calidad ha mermado sus hatos, pero estos acontecimientos no sólo se producen por las transformaciones generales del clima. Las mineras han intervenido en la zona, agravando el proceso de desertificación que se registra en estos sectores y alterando el ritmo de la vida pastoril local. Las peticiones de derechos de agua, tanto para relave como para consumo en los campamentos extractivos, han ido paulatinamente encontrando eco en la División General de Aguas, cuyas concesiones se han materializado en la construcción de bocatomas como la de Lequena (creada en 1967 y que abastece a Calama y Chuquicamata), la canalización y represa de San Pedro (1912), la aducción de Quinchamale (inaugurada en 1989) y el Embalse Conchi (1969). A consecuencia de estos trabajos, se ha mermado notoriamente el caudal del río Loa, desecándose incluso algunos de sus afluentes, siendo el más importante de ellos el río San Pedro, ya que en su confluencia con el Loa se formaba espacio geográfico caracterizado por un ensanchamiento del piso del valle con una amplia vega.

Su desecación explica algunos cambios en las estrategias de pastoreo, en particular, y de subsistencia, en general. Los circuitos de trashumancia se han ido perfilando cada vez más a la permanencia en la vega de caja de río, transitando por el mismo valle o sin apartarse mucho de los recursos de agua permanente que éste ofrece, limitándose así la extensión territorial de las estancias pastoriles y produciendo el paulatino abandono de la explotación de los pastos de lluvias. A esto se le debe sumar las presiones ecológicas experimentadas por las áreas vecinas, las que han expulsado a algunos grupos de estancieros de sus zonas tradicionales, obligándolos a adoptar un modo de vida 
nómade, de tipo trashumántico. Son éstos los que se han introducido bajo un modelo de uso del espacio extensivo, y que explotan el forraje disponible en las localidades que han experimentado un proceso de despoblamiento, o que comparten los derechos de uso que tienen las UPD de sus familiares.

Así los pastores se han visto obligados a concentrarse en los escasos recursos de agua disponibles de forma estable, mientras que a la par reciben las presiones de los administradores de las captadoras de agua, los que aducen que el ganado ensucia la poca agua que forma el caudal del Loa, tratando de obligarlos a que abandonen el pastoreo e incluso la localidad. Todas las UPD con las que hemos trabajado han denunciado este hecho, aun cuando no nos han explicitado cuáles son los mecanismos de coerción que han empleado; sin embargo, parece ser que la amenaza y la prohibición del uso del agua del río Loa, aludida como propiedad privada y cuyo uso legal le pertenece a los centros mineros o urbanos, la forma más común con que se concretiza. El miedo ha conducido a algunos estancieros a disminuir sus ganados, evitando las cruzas de sus animales, e incluso les ha llevado a evaluar la posibilidad de migrar definitivamente hacia Calama, abandonando su estancia y su actividad productiva tradicional.

Uno de los entrantes ${ }^{1}$ que llegó a ser uso del antiguo asentamiento de Santa Bárbara durante una década, sucumbió a estas presiones y emigró a Calama. Su situación en la ciudad, en la que no podía circular libremente por desconocer el entorno -no manejaba el sistema de intercambio monetario de manera fluida-, y su analfabetismo imposibilitaron su adaptación al nuevo entorno. Así, su situación actual es de permanente tránsito, entre las estancias de sus compadres en el Alto Loa, en las que colabora en las labores cotidianas como un miembro más, y con algunos de los cuales mantiene una mediería de crianza de burros. Como agente de aculturación (sensu Aguirre

Etnocategoría que utilizan los habitantes del sector para diferenciar a las familias originarias de cada localidad (vivientes) de las que han llegado a vivir allí, independientemente del tiempo de residencia que ya tengan en el lugar.
Beltrán 1957), ha jugado un papel importante en establecer lazos con la urbe y, a la vez, reforzar las reacciones contraaculturativas que han impedido que los demás estancieros abandonen el valle, pues se ven reflejados en la experiencia de otredad y extrañamiento que produce el centro urbano.

\section{Impacto simbólico y social de las extracciones de agua}

La vida de los estancieros del Alto Loa sigue siendo trastocada, como antaño, no sólo en sus medios de producción y, por tanto, en su desarrollo económico, sino también en su dimensión simbólica y orgánica social. Su relativa cercanía a puntos fronterizos, especialmente con Bolivia, favoreció por años y, por qué no decirlo, por siglos el tráfico material y simbólico con los habitantes del vecino país, población con la que, más allá de las divisiones administrativas actuales, siempre ha mantenido estrechos lazos sociales, económicos y culturales (Martínez 1998). Sin embargo, bajo el gobierno militar, como parte de la doctrina de la Seguridad Nacional y de resguardo del territorio patrio, las zonas fronterizas fueron reforzadas con contingente militar cuya función principal era controlar el flujo de población y mercadería entre Chile y los países aledaños. Una de las medidas adoptadas fue la declaración de ilegalidad del tráfico caravanero que utilizaba llamas como animal de carga, prohibición que se enmarca en la dificultad para controlar las diversas rutas que son capaces de transitar animales como éstos en comparación con las caravanas de mulas y burreros que sólo pueden cruzar por pasos de baja altura, de mayor identificación y, por lo mismo, más fácil de controlar. Conjuntamente con los cambios de las prácticas económicas tradicionales de los estancieros altoloínos, el sistema de represión se extendió a los planos simbólico-rituales, sufriendo persecuciones y diversos tipos de presiones que iban en pro de estimular el abandono de los ceremoniales tradicionales, especialmente los de raíces andinas, tanto por constituir elementos de cohesión social suprafamiliar como por reforzar las estrechas vinculaciones con la población boliviana y el tráfico de elementos de carácter ritual poco comprendido y menos aún valorados por la sociedad mayor, como son los paquetes y las hojas de coca, entre otros tantos. De esta manera, y aunque 
no hay ley en que puedan ampararse estos hechos, en la práctica se produjo un nuevo "proceso de extirpación de idolatrías". Las diversas comunidades indígenas del Norte Grande se vieron forzadas a esconder la realización de sus ceremonias e incluso a abandonarlas.

Puede parecer una magnificación de la situación vivida, pero según las propias palabras de don Luis, el conocedor que asiste a los ceremoniales desarrollados en muchas localidades del Alto Loa, surge con claridad la fuerza que debió tener este control social.

\section{...dejamos por años de hacer costumbre, muchos ya no hicieron, no nos dejaban hacerlas, nos perseguían, había que escon- derse... por eso muchos ya no se acuerdan de cómo hacer costumbre...}

El repliegue de estas prácticas hizo suponer por años su ausencia y en algunos casos las presiones lograron el efectivo abandono de ellas, relegándolas al status de "cosas de los antiguos", llegando casi a extinguirlas en el sector. Hoy intentan recuperarlas, tratando de ganarle a la torpeza del olvido, labor ardua y llena de dificultades, más aún cuando consideramos que las nuevas generaciones no conocieron más que de oídas la importancia de su periodicidad y no han podido vivenciar en lo cotidiano los vínculos con la dimensión sagrada que solía envolver a las comunidades altiplánicas. Estas experiencias compiten contra el continuo y legitimado mundo de las tradiciones occidentales modernas, que inculcan los medios de comunicación de masas a los que tienen acceso tanto por sus viajes como por su permanencia en los centros urbanos cercanos en los que reciben la instrucción primaria.

Para el caso de nuestras comunidades hay que tener presente al menos dos situaciones: las festividades comunales de los santos patrones y los rituales familiares de propiciación de ganado.

Las festividades comunales ligadas a la actividad ganadera que involucran a los pastores de Pastos Grandes y Santa Bárbara se reducen a la celebración de los santos patronos San Antonio Llamero y San Juan Bautista -patrono de los corderos-. No contamos con datos históricos sobre las cere- monias y ritos realizados en torno a San Antonio, salvo que se realizaba, al igual que hoy, en el pueblo de San Pedro Estación (asentamiento surgido con la construcción del ferrocarril Antofagasta-Oruro) y que entre sus manifestaciones religiosas figuraba el baile de los llamichos, actualmente extinto. Pese a ello podemos señalar que la estructuración de esta festividad se ha visto alterada con la llegada de integrantes de otras comunidades que encontraron en San Pedro Estación un refugio en donde poder celebrar sus ancestrales rituales de propiciación del ganado camélido. Estas familias provienen de Cupo y han construido su propia capilla en la que guardan la imagen del santo patrono, manteniendo así cierta independencia con respecto a los pastores del valle del Loa (desde Lequena hasta Chiu Chiu) que se congregan en una construcción de mayor tamaño, el templo, que tiene su propia imagen de San Antonio. Esta independencia se manifiesta también en los sistemas de cargo, ya que existe una duplicación de alferados, uno para atender a cada "centro ritual" y las personas que éste convoca.

Con respecto a la festividad de San Juan, conmemorada en el pueblo de Conchi Viejo, hay que recalcar su paso de fiesta comunal a una de carácter familiar, con las presiones vividas en las décadas de los '70 y '80. Sólo con los cambios generales que experimentó el país en esta última década del siglo, la celebración del santo patrono ha logrado tener una cobertura como la de antaño, congregando a los que han emigrado a Calama y Chuquicamata, a los comuneros de Lasana y a los pastores del Alto Loa. En los rituales que se despliegan con esta ocasión abundan los rasgos sincréticos: luminarias y fogatas, waquis, bodas y entradas de la cera, se realizan en honor a los patronos y a la Virgen del Carmen, ritos que se complementan con una misa y peregrinación de formalización cristiana. Entre los ruegos se reiteran los que se relacionan con las peticiones de lluvias y pasturas abundantes, así como la solicitud de bendiciones manifestadas en el multiplico del ganado. Estas súplicas se elevan al dios cristiano y a la "naturaleza", nombrada genéricamente, mientras se asperja con agua bendita hacia el este, donde se visualizan los mayores cerros que rodean el asentamiento. 
En su dimensión familiar, que corresponde a la víspera, es evidente el ruego que se hace a la Pachamama y al potencial protector del santo patrono. Se prepara una fogata frente al corral principal y a ambas entidades sagradas se les da de beber derramando un poco del ponche caliente, que se ha preparado especialmente para esta ocasión, sobre la tierra o el fuego, respectivamente. También es en este ritual familiar en donde se devela su claro valor genésico o propiciatorio de tipo ganadero: el jefe de la UPD construye pequeños corrales junto a la fogata con las piedras del suelo, dejando un segmento sin cerrar y "espera a que se llene", mientras sigue la tinka del santo patrono, para luego cerrar el corral "ahora lleno, gracias al multiplico" que ha propiciado San Juan.

En la actualidad, el pueblo de Conchi Viejo está viviendo una de sus etapas más duras, en términos de su continuidad como nucleador de la actividad religiosa y de la identidad de los habitantes de Santa Bárbara, puesto que la activación del mineral El Abra ha comprometido ese espacio, la libre circulación hacia el lugar e incluso su topografía, ya que el pueblo y algunas de sus estaciones rituales han quedado cortadas por un camino por donde transitan constantemente camiones con material extraído desde la mina. Hasta el momento no ha impedido que se sigan celebrando las festividades rituales tradicionales, pero puede que éstas se vean afectadas o, al menos alteradas, por el cambio del entorno social de pastoril a minero.

Pese a lo que pudiese creerse, la presión del mineral que quiso formar su campamento en el poblado gatilló, en la población que se identifica con él, la necesidad de defenderlo, para lo cual tuvieron que darse una orgánica que les permitiera enfrentar a esta empresa y defender sus derechos. Este proceso culminó en 1998 con el reconocimiento estatal de su calidad de comunidad indígena, con el nombramiento de Conchi Viejo como "pueblo típico" y con la declaración de Monumento Histórico de su capilla. Si bien a la percepción de ellos estas normalizaciones no les parece del todo favorables, saben que ahora están en un mejor pie para mantener el control cultural de sus sitios rituales.

Tomando en consideración las transformaciones que se han producido en las manifestaciones ri- tuales comunales, creemos que son de importancia central los ritos familiares, menos expuestos al control y a la intervención de la sociedad nacional. Como las UPD del sector bajo estudio presentan una orientación mayoritariamente pastoril, creemos que el rito familiar de mayor relevancia es el floramiento y marca del ganado ${ }^{2}$. Este ritual se enmarca con claridad en las tecnologías simbólicas andinas, ya que si bien es una instancia en que se señala la propiedad de cada uno de los animales que forman el rebaño que se pastorea familiarmente, es también un momento en que se paga a los seres dadores y protectores del ganado: los antepasados, la Pachamama y los cerros. Se produce también, con ocasión de este ceremonial, un desdoblamiento del espacio físico en un lugar sacro, transformación que es posible gracias a los sahumerios y ruedos realizados por el conocedor en compañía de todos los asistentes al ritual, ya sea en su categoría de pariente, de visita o forastero.

Los pagos tienen lugar en varios espacios y en distintos momentos del extenso ritual (que puede durar hasta 5 días, dependiendo del número de cabezas y variedad de especies que conforman los hatos familiares). Hay waquis en la noche de vísperas, cuyo destino final no pudimos establecer; hay ofrendas en hojas de coca, licor y harinas de quínoa y pak'o (Oxiychloe andina) en una piedra ritual ubicada en el interior del corral y hay ofrendas a los cerros que se hacen en oquedades cavadas en un lugar en que se pueden apreciar tanto los recursos forrajeros como hídricos con que cuenta la estancia.

Las rogativas son siempre similares: aumento del ganado, prosperidad y salud para sus dueños, son los versos que acompañan cada tinka y que se han de repetir en la invocación a los cerros y en las oraciones proclamadas frente a las imágenes cristianas de devoción que guardan en un altar especialmente preparado.

Estos rituales de habían dejado de realizarse por casi dos décadas en las estancias de Santa Bárba-

En esta zona de los Andes, estos ritos, que tradicionalmente forman parte de un único ceremonial, pueden darse en instancias distintas, dando origen a dos rituales diferenciables en tiempo y espacio. 
ra y Pastos Grandes. La férrea convicción de que la sequía que los asolaba era porque habían abandonado su costumbre, rompiendo su reciprocidad con los seres tutelares, les llevó a retomarlas, esperando recuperar los lazos rotos y contar nuevamente con la protección de sus cerros, el gobernador Illiani (Bolivia) y su alcalde, el Palpana.

Esta no ha sido la única actividad ritual que se ha retomado en los últimos años como reacción cultural frente a la sequía. En algunas estancias, los pastores recuerdan algunos rituales de rogativa para pedirle a los cerros que venga la lluvia tan ansiada como necesaria. Haciendo uso de sus redes de contacto -en la que nosotros empezamos a formar parte-consiguen agua de mar, para luego asperjarla en la punta del cerro tutelar de la comunidad: el Palpana. Como toda prefiguración (sensu van Kessel 1976), su realización es un acto cuya eficacia es directa y real. El agua de mar, imagen de la gran mamacocha se asocia a las lluvias y a las características meteorológicas de los cerros, por lo que la aspersión es una imagen de las precipitaciones. El efecto real no puede variar del de la prefiguración; si no llueve es porque algo no se hizo bien en el ritual... El caso concreto es que al rito le siguieron unas pocas lluvias de altura, que permitió el crecimiento de una mediana cubierta vegetacional de pastos en el cerro en cuestión, que fueron aprovechadaS tam»o por los estancieros del sector como por los animales silvestres. La poca duración de esta área de forraje fue asumida como escasez del agua asperjada o por que ya era agua vieja, dado que el ritual requiere realizarse antes de 15 días de la extracción del agua de mar, porque luego pierde su poder. Para ellos no existe coincidencia, sino que es producto de una relación necesaria entre el ritual y su efecto.

Por otra parte, no podemos dejar de mencionar que su percepción simbólica del entorno ha llevado a unir en relación de causalidad directa los trabajos de extracción de agua y la reticencia de los cerros a enviar lluvias.

los mallkus, los cerros nuestros están molestos... no hay lluvia porque los van a molestar con esas máquinas que les echan como rayos pa'dentro pa'ver si hay agua... Siempre andan buscando agua y joden a los cerros con electricidá... por eso ellos no quieren darnos agua... por eso no hay pasto, nada verdea en los cerros...

Así, entre las presiones medioambientales y las de las extracciones mineras, la percepción de los estancieros sobre su entorno y la disponibilidad de recursos que éste les ofrece, oscila entre una práctica productiva cada vez más orientada a la supervivencia y al intercambio económico de mercado, y una reactivación de las tecnologías simbólicas, en pro de restablecer el equilibrio perdido con la naturaleza.

\section{Cultura y medio ambiente: hacia una evaluación de impacto}

Tras esta caracterización ecológica y cultural de los sectores de Santa Bárbara y Pastos Grandes, aparece como innegable la estrecha vinculación económica y simbólica de la percepción del entorno de esta comunidad, la que ya no podemos clasificar sólo de etnobotánica, puesto que cruza muchas otras dimensiones más: la orográfica, la hidrográfica, la climática y la productiva, por mencionar sólo las más evidentes.

Ahora, lo que importa es esbozar cómo esta percepción se está viendo afectada por las transformaciones que está experimentando el medio ambiente y las relaciones de autarquía de la comunidad bajo estudio, transformación e impacto que aquí abordaremos en conjunto.

La comunidad de Conchi Viejo presenta una orgánica aparentemente desarticulada: un conjunto de unidades familiares en una serie de caseríos dispersos, que se mantienen en relativa independencia unos de otros. Sin embargo, existe una serie de normativas que los estructuran como comunidad.

En primer lugar, destaca los sistemas consuetudinarios de distribución y respeto de usos de áreas de forrajeo discretas en un espacio continuo, como es la vega de caja de río. Cada estancia conoce el radio de explotación sobre el que tiene derechos, radio que en tiempos de mayor presión de carga -por la presencia de un número mayor de estancias activas- contó con un sistema físico de deslindes, sin que llegara por ello a considerarse propiedad privada de las respectivas estancias pasto- 
riles. Así también pareció existir un sistema análogo de uso comunitario de las pasturas temporales o estacionales del cerro y la pampa, acordando un uso equitativo, en cuanto acceso, a este preciado recurso. Con estos datos podemos configurar con claridad la primera dimensión comunal ya que han organizado las zonas de recursos naturales fundamentales para la producción ganadera, pudiendo reconocerse una red de derechos de uso que no implican propiedad privada de las zonas de pastura.

Por otra parte, esta UPD, que articulan gran parte de sus actividades productivas sólo por redes parentales, mantienen sistemas de reciprocidad más allá de estos marcos, en labores de gran esfuerzo, como es la techumbre de las casas, la construcción y mantenimiento de canales de regadío y las marcas del ganado. Así, organizan y controlan los recursos sociales esenciales para la reproducción del sistema, representado básicamente en la reciprocidad, que enmarcan y evocan en la realización de actividades rituales que requieren de ejecuciones colectivas. Además, tienen manifiestas prácticas de control social vía sanción moral y apartamiento de la comunidad de aquellos miembros que no respetan los acuerdos comunes o que tienen una conducta que es reprochable, moral o productivamente. Estas sanciones no se concretizan en acciones punitivas, dado que se les ha impuesto un sistema jurídico nacional como forma de solución a sus disputas, las que al ser ineficientes para el control del equilibrio productivo pastoril o de los rasgos básicos de su cultura pasan a ser letra muerta en las comunidades altoloínas.

Siguiendo en la lógica de articulación social de los comunitarios, las familias de Santa Bárbara y Pastos grandes mantienen un sentido de identidad y pertenencia, reconociendo la existencia de un lugar común, un nucleamiento que es más bien de carácter ritual que práctico-cotidiano, en el pueblo de Conchi Viejo, y en la actualidad su calidad indígena como parte de la comunidad homónima. En ese lugar refuerzan los lazos comunitarios incluso con aquellos que aparentemente han desertado de este sistema social, los que han migrado a las ciudades y poblados vecinos en busca de fuentes laborales más rentables. Estas personas operan bajo un sistema de contacto aculturativo
(Aguirre Beltrán 1957: 34), en el que aparentemente se han asimilado a la cultura dominante en la que participan; al menos en su estructura productiva mantienen un sentido de pertenencia real -manifestado en apoyo económico a sus familiares que permanecen en las estancias- y simbólico, reactivando sus relaciones con la cultura madre en ocasiones rituales, tanto de convocatoria familiar (floreo) como en festividades comunales, como es la de los santos patronos. En estas últimas, participan no sólo con su asistencia presencial sino que se integran activamente a los sistemas de cargo que hacen posible su realización, principalmente en el rol de alferados.

Ahora bien, con respecto a la defensa de intereses comunes, se ha producido un fenómeno social de relevancia. La situación de contacto aculturativo, con características de zona de frontera cultural, ha activado esta dimensión, que en grupos dispersos como el estudiado no suele tener manifestación. Este aspecto debemos analizarlo conjuntamente con el segundo nivel de expresión de la organización comunal, que es el político y social.

Si bien la comunidad de Conchi Viejo no cuenta con una Asamblea Comunal, situación explicable por su orientación económica pastoril (tiende a la dispersión de sus miembros en un amplio territorio en vez de concentrarlos en torno a un poblado, como ocurre con las comunidades mixtas en las que la agricultura juega un rol tan importante como la ganadería), sí mantiene algunos sistemas de cargo y de representación en los que los estancieros altoloínos participan indirectamente, ya que sus núcleos familiares se han reducido y muchos de sus familiares viven fuera del sector, y son los que ejercen cargos en ella. Estos parientes, que actualmente viven en la ciudad, han tomado contacto con miembros de las comunidades más cercanas -vinculación autodefinida que los conecta con la población de Lasana- y con ellos participan en la lucha por la defensa de sus derechos como "atacameños", buscando espacios de expresión y apoyo en la Conadi regional. Su actual status de Comunidad Indígena les ha conducido gradualmente hacia otras luchas reivindicativas, siendo su principal punto de congregación y bandera de lucha el agua, recurso fundamental para el desarrollo de las comunidades altoandinas, pero cuya defensa se dificulta por las condiciones jurídicas 
en que se encuentran y la baja presión que pueden ejercer si se considera el número de afectados, factor que entra en juego en las mediciones de costo social de cualquier proyecto.

Los estancieros altoloínos no cuentan con la propiedad formal de las tierras que habitan ni de las áreas que explotan. Estos terrenos se consideran de propiedad fiscal, cuyo goce recae en los habitantes tradicionales del sector, pero las decisiones básicas sobre sus recursos naturales son estatales ${ }^{3}$. Recordemos que no existen concesiones de derechos de agua que recaigan en los estancieros ni en las comunidades agrícolas emplazadas río abajo. De esta manera, el desarrollo minero ha podido acceder al control de gran parte de los acuíferos de la región, en perjuicio de las comunidades rurales campesinas. A partir de la formulación y puesta en vigencia de la Ley Indígena (Ley $\left.\mathrm{N}^{\circ} 19.253\right)$ tanto los agricultores de Lasana como la comunidad de Conchi Viejo han emprendido esfuerzos en pro de la defensa de sus recursos fundamentales, intentando ejercer una mayor presión política y jurídica, dada su nueva orgánica.

Esta situación de presión aculturativa y medioambiental, por la desecación, ha producido algunos cambios al interior de la comunidad que no podríamos denominar como desarticulación. Lejos de ello, ha reforzado su estructura de base, en sus niveles más difusos, como es lo comunal, en una comunidad no nucleada en términos de patrón de asentamiento.

\section{Consideraciones finales}

El proceso aculturativo no actúa de la misma manera en todos los niveles de la cultura: las presiones medioambientales guardan directa relación con el desarrollo económico de una comunidad determinada; sin embargo, el fenómeno de reinterpretación cultural se presenta como un foco de resistencia a los cambios que propicia -directa o indirectamente- la sociedad nacional. Así, el

A fines de 1998, los estancieros de los sectores de Pastos Grandes y Santa Bárbara iniciaron la tramitación de títulos de dominio de goce ante el Ministerio de Bienes Nacionales, proceso que no podrá ser resuelto con demasiada prontitud debido a la superposición de solicitudes entre los comuneros problema de la etnopercepción del espacio y sus transformaciones, en definitiva, las lecturas simbólicas que realizan de los fenómenos de cambio, dan algunas claves para entender este fenómeno y evaluar una nueva dimensión del impacto de la reducción del agua y los recursos que están estrechamente asociados a ella y que amplía la mirada tradicional, que se centra en los aspectos tecnoeconómicos.

Si bien debemos reconocer que el proceso de desecación que experimenta la región pone en peligro la continuidad de las estancias pastoriles altoandinas, forzando a la migración y al abandono paulatino de los modos tradicionales de producción, el fenómeno ha producido un efecto de refuerzo cultural, sólo explicable en la estrecha relación de percepción ecológico-simbólica que presentan estas comunidades. Así, el proceso de aculturación económica ha traído aparejado uno de contraaculturación simbólica, con el refuerzo y reactiv`øión de las prácticas rituales tradicionales, que han llevado a un fortalecimiento del nivel comunal de la comunidad bajo estudio.

Aún así, sigue vigente la nota de alerta frente a la posible desestructuración de estos modos de vida, dado que cada día más niños son tempranamente separados de la comunidad, siendo muy bajo su nivel de socialización con los aspectos culturales propios: visión de mundo, en la que se enmarca la percepción del entorno natural y su vinculación con el mundo sobrenatural. Así, estas comunidades hoy fortalecidas pueden perder vigencia en las próximas generaciones cuya aculturación selectiva e integración alternativa tienda hacia la transformación de estas culturas apropiadas en culturas enajenadas. Estos efectos pueden ser minimizados si, haciendo uso de la legislación indígena vigente, se logra una delimitación de su espacio vital, que comprende los terrenos básicos para su subsistencia económica: los radios de forrajeo de caja de vega, las laderas de los cerros como áreas de explotación estacional, cuya protección debe incluir la fuente que hace posible el mantenimiento de una cubierta vegetacional, el agua. Además, debe contemplar que la subsistencia cultural de estas comunidades pasa también por el libre acceso a los puntos de significación simbólica, como los pueblos de Conchi Viejo y San Pedro Estación, y a la mantención de las características 
orográficas regionales, cuyos cerros son considerados como seres tutelares, especialmente el caso del Palpana.

La consideración de estos otros aspectos puede ayudar a encontrar caminos para la implementación de proyectos de etnodesarrollo o de desarrollo local para comunidades específicas, como son los estancieros altoloínos, entregando herramien- tas para el diálogo y la generación de convenios o conciliación de intereses, con los cuales el progreso y crecimiento del país no implique un notable desmejoramiento de la calidad de vida de estas poblaciones. Por otra parte, se permitirá evaluar con mayor precisión la pérdida o crisis de identidad que estarían viviendo las comunidades andinas y buscar fórmulas que las reactiven, asegurando su futuro.

\section{BIBLIOGRAFIA}

AGUIRRE Beltrán, G. El proceso de aculturación. Univer1957 sidad Nacional Autónoma de México. México.

ALDUNATE, C. Desecación de las Vegas de Turi. Revista 1985 Chungará 14. Universidad de Tarapacá, Arica.

ALDUNATE, C y V. CASTRO. Las chullpas de Toconce y 1981 su relación con el poblamiento altiplánico en EI Loa Superior. Período Tardío. Tesis para optar al grado de Lic. en Arqueología y Prehistoria. U. de Chile. Santiago.

ALDUNATE, C.; J. ARMESTO, V. CASTRO y C. 1981 VILLAGRAN. Estudio Etnobotánico en una comunidad Precordillerana de Antofagasta: Toconce. Boletín del Museo Nacional de Historia Natural 38. Chile.

ALDUNATE, C.; J. BERENGUER, V. CASTRO, L. CORNE 1986 JO, J. MARTÍNEZ y C. SIN-CLAIRE. Cronología y Asentamiento en la región de EI Loa Superior. Universidad de Chile, Santiago.

BINFORD, L. The Archaeology of Place. Journal of 1982 Anthropological Archaeology 1 (1).

BONFIL, G. Pensar nuestra cultura. Alianza Edi1991 torial, México, D. F.

CASASSAS, J.M. La región atacameña en el siglo XVII $1974 \quad$ Universidad del Norte. Antofagasta.

CASTRO, M.; M. BAHAMONDES, y P. AZOCAR. Carac1991 terización Antropológica de las poblaciones andinas de la I y II Región. Chile. Universidad de Chile, DGA MOP. Santiago.
CASTRO, V., C. ALDUNATE, J. BERENGUER, L. CORNE1994 JO, C. SINCLAIRE y V. VARELA Relaciones entre el noroeste argentino y el norte de Chile: El sitio 02-tu-002, vegas de Turi. Actas y Memorias Simposio Relaciones Costa- Selva, Argentina.

CASTRO, V. y J. L. MARTINEZ. Poblaciones indígenas de 1996 Atacama. En: Etnografía. Sociedades indígenas contemporáneas y su ideología. Hidalgo et al. (Eds.). Ed. Andrés Bello. Santiago.

CASTRO, V. y V. VARELA (Eds.). Ceremonias de Tierra y 1995 Agua. Ritos milenarios andinos. FONDART, MINEDUC y Fundación Andes. Santiago.

CAVIERES, A. Política de Aguas y comunidades indí1995(Ms) genas del altiplano. Ciencia Indígena, Castro et al. (Eds.). Santiago (en preparación).

CIREN-CORFO. Estudio de los recursos hídricos de la 1973 cuenca del río Loa. Universidad de Chile, Corfo. Santiago.

CONSECOL. Plan de desarrollo regional segunda 1988 Región. Serplac, Antofagasta.

DELANO, P. Aspectos socioeconómicos de una co1982 munidad del norte grande: Caspana. Tesis para optar al grado de Licenciado en Antropología Social, Facultad de Humanidades, Universidad de Chile, Santiago.

ESSAN Plan de desarrollo para los servicios 1992 de agua potable y alcantarillado de Essan S.A. Definición del proyecto de inversión. Santiago. 
FLANNERY, K.; J. MARCUS y R. REYNOLDS. The flocksof 1989 the Wamani. Academic Press. Inc. U.S.A.

FLORES OCHOA, J. Pastores del Ande Sur-Peruano. Revis1964 ta de la Universidad Técnica del Altiplano 2. Puno. su estudio. Instituto Indigenista Interamericano. Serie Antropología Social $\mathbf{N}^{\circ}$ 10. México.

1983 Pastores de llamas y alpacas en los Andes -balance bibliográfico-. Revista Andina 1 (1).

GOMEZ, C. La comunidad campesina indígena 1980 del Loa Superior. Tesis de grado para optar al título de Licenciatura en Ciencias Antropológicas, Universidad de Chile, Santiago.

GUNDERMANN, H. Ganadería Aymara, Ecología y Forra1984 jes: evaluación regional de una actividad productiva andina. Chungará 12 .

GUNDERMANN, H. y H. GONZALEZ. Tierra, agua y socie1995 dad atacameña, un escenario cambiante. En: Agua, ocupación del espacio y economía campesina en la región atacameña, Pourrut y Núñez (Eds.). Universidad Católica del Norte, ORSTOM. Antofagasta.

HIDALGO, B. Organización Social, Tradición y 1992 Aculturación en Socaire. Memoria para optar al título de antropólogo. Departamento de Antropología, Universidad de Chile, Santiago.

MARISCOTTI, A. Pachamama Santa Tierra. Contribucio1978 nes al estudio de la religión autóctona en los Andes centro-meridionales. Indiana Suplemento n. 8. Berlín.

MARTINEZ, G. El sistema de los Uywiris en Isluga. En: 1976 Homenaje al Dr. Gustavo Le Paige, s. j. Universidad del Norte. Santiago.

MARTINEZ, G. Los dioses de los cerros en los Andes. 1983 Journal de la Société des Americanistes t. LXIX. París.

MERLINO, R. Pastoreo y agricultura en el altiplano 1979 meridional: aspectos cosmovisionales y religiosos. Trabajo presentado al III Congreso del Hombre y la Cultura Andina. Cuzco.

MERLINO, R. y M. RABEY. Pastores del altiplano andino 1983 meridional: religiosidad, territorio y equilibrio ecológico. Allpanchis 18 (21). Cusco.
MOSTNY, G. y G. KUNSEMULLER. Informe preliminar de 1960 la expedición al río Loa Superior. Noticiario mensual del Museo Nacional de Historia Natural 44, Santiago.

NUÑEZ. L. Desarrollo cultural prehispánico en el 1965 norte de Chile. Estudios Arqueológi$\cos 1$, Antofagasta.

1995 Evolución de la ocupación y organización del espacio atacameño. En: Agua, ocupación del espacio y economía campesina en la región atacameña, Pourrut y Núñez (eds.). Universidad Católica del Norte, ORSTOM. Antofagasta.

PALACIOS, F. Tecnología del pastoreo. En: La tecnolo1981 gía en el mundo andino. Lechtman y Soldi (Eds.). Universidad Nacional Autónoma de México. México, D. F.

1988 Tecnología del pastoreo. En: Llamichos y paqocheros. Pastores de llamas y alpacas. Flores Ochoa (comp.). Centro de Estudios Andinos Cuzco, Cuzco.

PLAZA, O. y M. FRANCKE. Formas de dominio, econo1981 mía y comunidades campesinas. Desco, Lima.

POURRUT, P. El desierto, el hombre y el agua, Pro1995 blemática regional en torno al agua. En: Agua, ocupación del espacio y economía campesina en la región atacameña, Pourrut y Núñez (Eds.). Universidad Católica del Norte, ORSTOM. Antofagasta.

POURRUT, P. y L. NUÑEZ. El agro y la identidad atacameña: $1995 \quad$ Entre la crisis y la esperanza. En: Agua, ocupación del espacio y economía campesina en la región atacameña, Pourrut y Núñez (Eds.). Universidad Católica del Norte, ORSTOM. Antofagasta.

PROVOSTE, P. Antecedentes de la estructura socio1976 económica de Isluga. Universidad del Norte, Iquique.

PROVOSTE, P. Diferenciación e integración social en el 1979 altiplano chileno. América Indígena vol. XLIX, No ${ }^{\circ}$, México.

REINHARD, J. Las montañas sagradas: un estudio etno1983 arqueológico de ruinas en las altas cumbres andinas. Cuadernos de Historia 3. Universidad de Chile, Santiago. 
RIVERA, F. 1995

El contexto histórico y social del manejo de los recursos agropecuarios en los oasis de San Pedro de Atacama. En: Agua, ocupación del espacio y economía campesina en la región atacameña, Pourrut y Núñez (Eds.). Universidad Católica del Norte, ORSTOM. Antofagasta.

ROMERO, H. Geografía de los climas. Serie Geo1985 grafía de Chile. Tomo XI.Instituto Geográfico Militar. Santiago.

ROMERO y RIVERA. Escasez y competencia por los recur1995 sos hídricos: necesidad de una evaluación estratégica ambiental. IV Jornadas de trabajo "Gestión de Recursos hídricos en zonas áridas”. Comité chileno para el programa hidrológico. Universidad Católica del Norte, Antofagasta.

RYDEN, S. Contributions of the archaeology of 1944 the rio Loa region. Elanders Boktryckeri Aktiebolag, Gotemburgo.

TOMOEDA, $\mathrm{H}$. La llama es mi chacra. El mundo me1988 tafórico del pastor andino. En: Llamichos y paqocheros. Pastores de llamas y alpacas. Flores Ochoa (comp.). Centro de Estudios Andinos Cuzco, Cuzco.

UNIVERSIDAD DE CHILE. Diagnóstico de la desertifi1997 cación en Chile. Universidad de Chile, Santiago.

URIBE, $M$. 1994

La cerámica arqueológica de Santa Bárbara Contextos de pastorescaravaneros en la subregión del Alto Loa (1200 - 1480 d.C.). Informe final de práctica profesional. Universidad de Chile, Santiago.

VALLEE, L. La ecología subjetiva como elemento 1970 esencial de la verticalidad. XXXIX Congreso Internacional de Americanistas, Actas y Memorias. Lima.
VAN KESSEL, J. La pictografía rupestre como imagen 1976 votiva En: Homenaje al Dr. Gustavo Le Paige, s. j. Universidad del Norte. Santiago.

1985 La lucha por el agua de Tarapacá: la visión andina. Chungará 14.

1990 Tecnología aymara: un enfoque cultural En: Tecnología andina. Una introducción. Medina, J. (Ed.). Hisbol. La Paz.

1992 El pago a la Tierra, porque el desarrollo lo exige. Allpanchis 23 (40). Cusco.

1996 Los aymaras contemporáneos de Chile. En: Etnografía. Sociedades indígenas contemporáneas y su ideología. Hidalgo et al. (Eds.). Ed. Andrés Bello. Santiago.

1996a La cosmovisión aymara. En: Etnografía. Sociedades Indígenas contemporáneas y su ideología, Hidalgo et al. (Eds.). Editorial Andrés Bello, Santiago.

VAN KESSEL, J. y D. CONDORI CRUZ. Criar la vida. Tra1992 bajo y tecnología en el mundo andino Vivarium, Santiago.

WATANABE, H. The ainu. Journal of the Faculty of $1964 \quad$ Science Tokyo 2 (6).

YACOBACCIO, H.; C. MADERO y S. CARACOTCHE 1994 "Ahicito nomas": un año de movilidad de los pastores puneños. En: Actas y memorias del XI Congreso Nacional de Arqueología Argentina, Revista del Museo de Historia Natural de San Rafael XIII (1-4). 


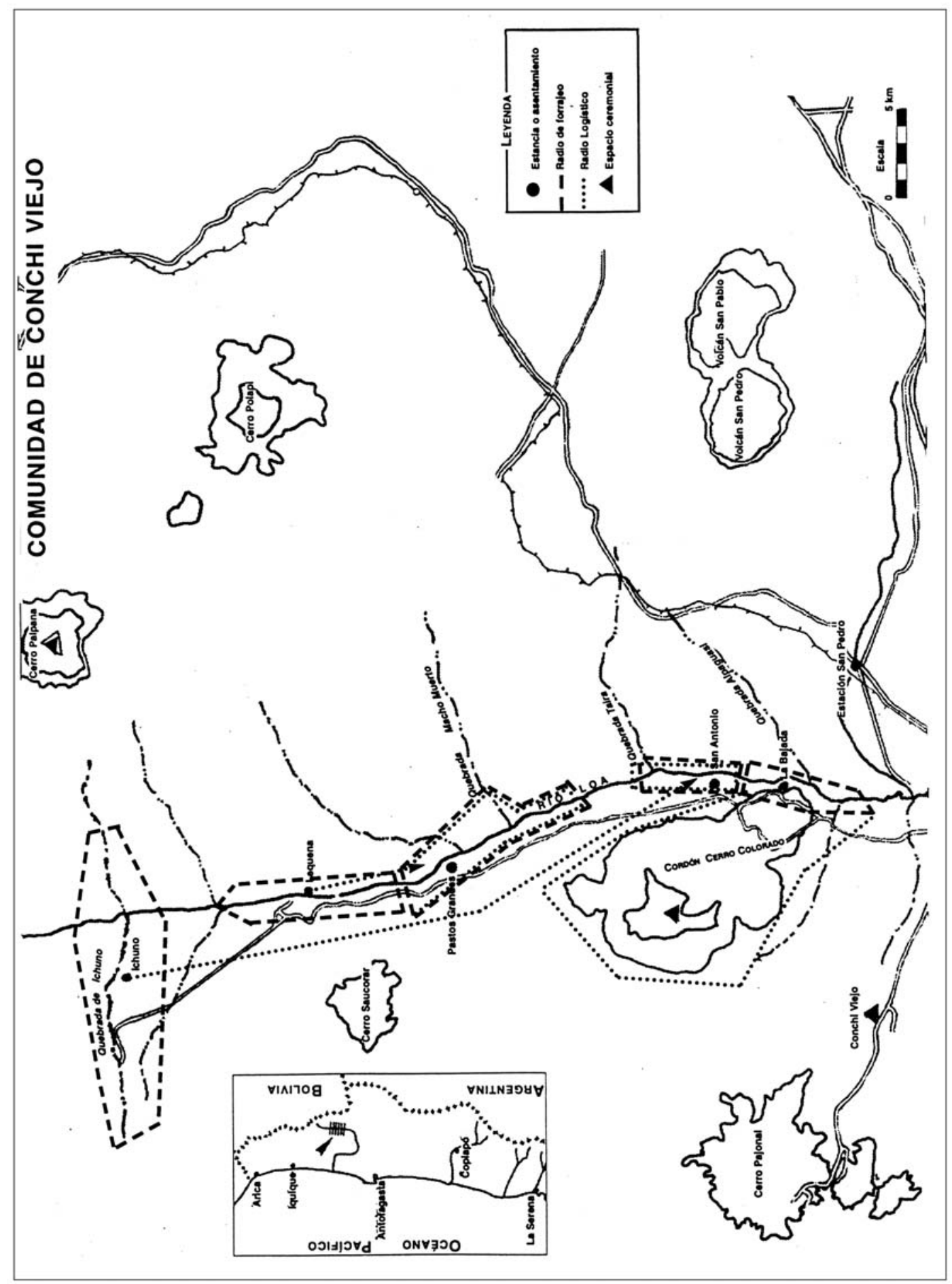

